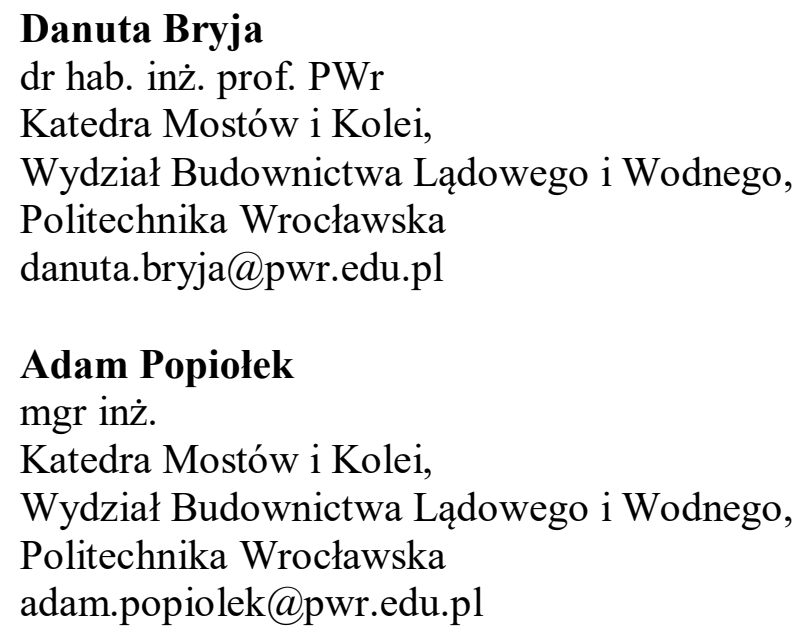

DOI: $10.35117 /$ A_ENG_17_06_04

\title{
Initial validation of the method for simulating the dynamic interaction between pantograph and overhead contact line
}

\begin{abstract}
The paper presents the results of initial validation of the method for simulating the dynamic interaction between a pantograph and a overhead contact line. According to European Standard EN50318, the first step of validation was done, which consists of comparison of the simulation results with limit values given in European Standard for the reference model. The dynamic behaviour characteristics, in terms of TSI ENE, were calculated from simulated vibrations of the ten-span overhead contact line and the pantograph, and the rate of contact force change in time. Geometrical and mechanical parameters of the overhead contact line and the pantograph were based on the annex to European Standard EN50318. It was proved, that the part of the characteristics meets European Standard requirements and the other slightly exceed the limit values. Based on the analysis, the direction of further research was proposed.
\end{abstract}

Key words: Overhead contact line; Pantograph; Dynamic interaction; Numerical simulation; Validation of simulation method

\section{Introduction}

Due to the intensive development of high-speed railway, new technical solutions in the field of rolling stock and infrastructure are sought in many countries around the world to improve the economic efficiency of rail transport, comfort of travel, reliability and safety. Also existing solutions are optimized and modernized in order to adapt to increased speeds of trains. These activities related to the pursuit of increasing the speed of train traffic have resulted in growing interest in the dynamics of railway infrastructure objects, including the railway traction network. The upper traction network of the railway traction has become the subject of research not only of the electric power industry, but also specialists dealing with the dynamics of the structure.

The second strong incentive for the development of research on the dynamics of road networks is the law introduced in the territory of the European Union, which aims to implement the principles of interoperability within the rail market in the Community. As in other areas of the economy, it is to lead to the creation of a single market with four basic freedoms, such as: the movement of people, capital, services and goods. In the railway sector, the last of these freedoms is particularly important, mainly regarding the mutual acceptance of 
products, with the notion of products being understood not only as movable goods, i.e. vehicles and their parts, but also infrastructure and its components.

Interoperability requirements are governed by the entire rail market in the European Union in the area of new and modernized components [5]. Under the Directive of the European Parliament and of the Council (EU) 2016/797 on the interoperability of the rail system in the European Union [3], the railway system has been divided into subsystems and interoperability constituents. They require the assessment of compliance with European requirements, made by the so-called notified bodies. The result is an EC verification certificate that allows the subsystem or interoperability constituent to be used.

The overhead contact line is part of the Energy subsystem (ENE). This is one of the so-called structural subsystems that are part of the railway. The technical conditions which must be met by the various elements of the subsystems, as well as descriptions of the methods of their verification, are included in the Technical Specifications of Interoperability (TSI). Requirements for the energy subsystem are contained in the Energy TSI [6] and mainly concern the parameters of the electric traction power supply system, but also the geometry of the overhead contact line, the pantograph gauge and the so-called dynamic characteristics and quality of current collection. Analysis of dynamic characteristics, i.e. dynamic interaction between pantograph and overhead contact line, is in the field of dynamics of construction because its verification is based on the assessment of dynamic contact force of the pantograph head on the contact wire, along with its statistical measures and assessment of vibrations of network elements and pantographs. The quality of current collection is expressed by the socalled percentage of loss of contact, which determines the share of time in which pantograph head contact loss with the contact wire in the total travel time through the test section of the network.

In accordance with clause 6.1.4.1 of the TSI Energy [6], assessment of conformity of the overhead contact line structure should be made in two stages. In the first stage, numerical simulations should be performed to determine the dynamic characteristics of the overhead contact line. Then, if the simulation results are within acceptable limits, a dynamic field test should be carried out. The first important problem in this process is the access to appropriate simulation software. Hence in recent years scientific research aimed at finding effective numerical models and computational algorithms that would give reliable simulation results with an acceptable time of its execution. A review of the worldwide methods of traction network modelling and simulation of network vibrations is presented in [1], while in [2] the authors formulate their own original computational model of the coupled dynamic system traction network - pantograph, which in [1] is used to analyse the vibrations of a composite lattice modelling a tensile traction network.

The subject of this article is the preliminary validation of the simulation method proposed in [1] and [2]. In accordance with the TSI Energy requirements, the validation of the calculation tool used to simulate the dynamic characteristics of the overhead contact line should be carried out according to EN50318 [4], which assumes two steps of this validation. In the first step, the results obtained for the so-called reference model using the "unproven" simulation method should be compared with limit values specified by the standard [4]. The second step consists in comparing the simulation results with the results of dynamic measurements carried out in the field or compared with the results obtained by means of other simulation methods authorized for use. This article describes numerical research concerning the first step of validation.

The paper presents an example of simulation of the dynamic characteristics of overhead contact network, as defined by TSI Energia, using the network and pantograph parameters specifying the reference model described in the EN50318 standard [4]. The method of selecting the remaining input quantities, not specified by the standard, was 
characterized. Simulation results were compared with the limits given in the standard, which should not be exceeded so that the result of the first step of validation of the simulation method is positive. It should be emphasized here that the validation results presented in the article are not yet final, because at the current stage of research, the computational capabilities of the algorithm described in [1] and [2] have not been fully exploited. However, it was shown that the preliminary results of the calculations are very similar to the expected ones, which justifies to undertake further research leading to the full validation of the proposed method.

\section{The method of numerical simulation of vibrations of the traction network - pantograph}

On the basis of the simulation method described in [1], based on the computational model of the traction network - pantograph system formulated in [2], an original computer program named "SiViPant" was developed. The program was written in the generally available DevPascal development environment, but it can be easily implemented into the integrated Delphi environment. The program enables simulation of vibrations of the contact line and pantograph and the pantograph head pressure on the contact wire, so-called contact force. The results of the simulations are a discrete record of the time series of the analysed result variables with a set time step. By numerical study of the designated runs, the output parameters required by the TSI [6] and the standard [4] describing the dynamic characteristics of the upper contact network are obtained.

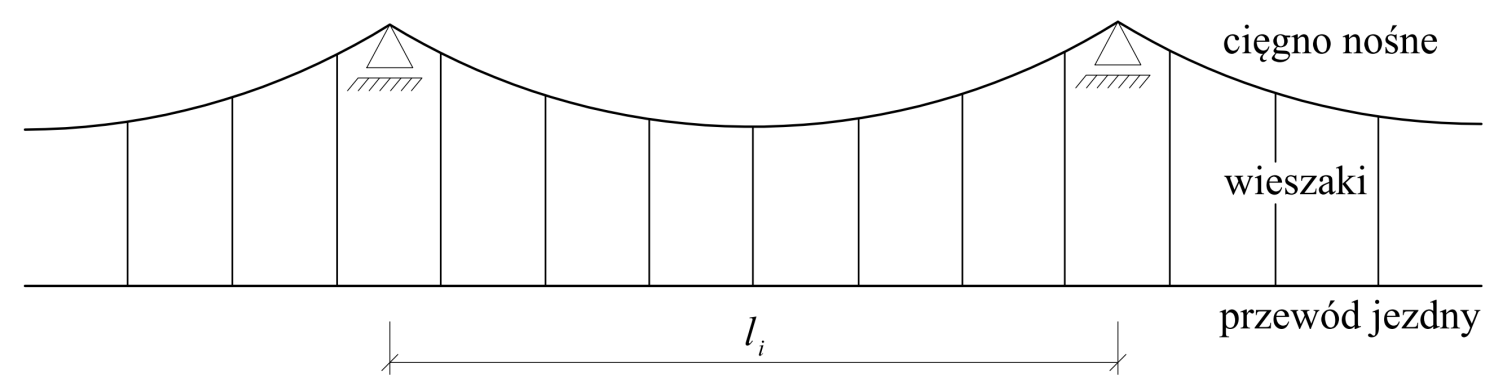

1. Diagram of the overhead contact line

The upper overhead contact line in the accepted calculation model of the overhead contact line consists of one carrier rope and one contact wire, connected by means of slatted wire type hangers, i.e. non-compressible (Figure 1). For modelling of the traction network, the theory of vibrations of the flaccid tendon and the approximation method of Lagrange - Ritz were applied. The physical model of the carrier rope is a linear-elastic flaccid tendon with continuous mass distribution, based horizontally on rigid supports. The contact wire is a linear-elastic string with a continuous weight distribution. Hangers are represented by elastic ties with non-zero stiffness at tension and zero at compression. Taking into account such behaviour of hangers is done by adding a non-linear component to the matrix equation of motion, which at the beginning is a linear equation. The nonlinear component of the equation compensates in the global stiffness matrix of the system those elements that correspond to the compression hanger in a given calculation step. Hangers are sought after by comparing the displacement of both ends of each of the hangers. This mechanism is described in detail in [1], along with mathematical formulas.

It should be noted here that the compensation component of the traffic equation in the presented algorithm is determined in each calculation step by means of a simple iteration, the ending of which should occur after obtaining the desired solution accuracy. For numerical research described in this paper, the number of iterations to one step was limited to shorten 
the calculation times at the initial validation stage of the proposed method. More detailed numerical analyses will be the subject of another publication.

The vibrations of the overhead contact line are forced by a pantograph moving along a constant speed network, or a set of two pantographs. It was assumed that the pantograph dynamic model is a discrete system consisting of two mass elements representing the receiving shoe and the articulated frame. These elements are connected by means of viscous dampers and elastic ties (Fig. 2). The vibrations of the network and the pantograph are coupled through the so-called a contact spring placed between the pantograph shoe and the contact wire, the use of which in the model is permitted by the standard [4].

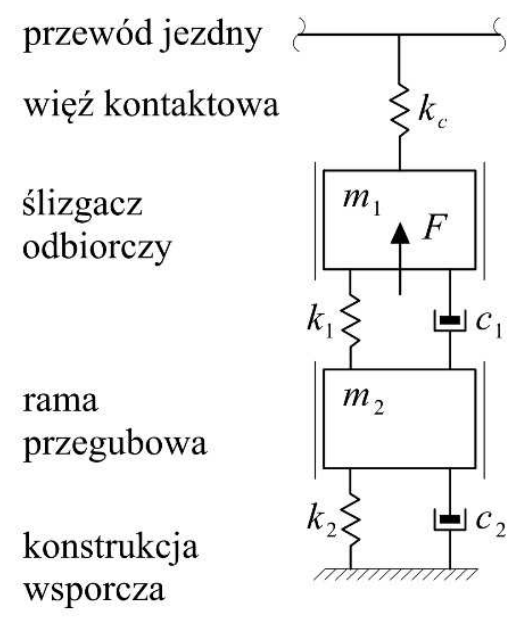

2. The pantograph dynamic model

The standard requirements for the first step of the validation of the calculation method According to the EN50318 standard [4], in the first validation step, the calculation method should be controlled using the so-called reference model. Validation consists in:

- the simulation of the dynamic interaction between the pantograph and the overhead contact line for the reference model using the proposed simulation method,

- comparison of simulation results with limit values included in the standard.

The simulation method should make possible to determine the following output data, which include a set of results defining the so-called dynamic characteristics of the overhead contact line:

- average value of the contact pressure force $F_{m}$,

- standard deviation of the contact pressure force $\sigma$,

- statistical maximum and minimum contact pressure, determined from the formulas $F_{m}+3 \sigma$ i $F_{m}-3 \sigma$,

- actual maximum and minimum contact pressure,

- statistical distribution, i.e. histogram of the contact pressure force,

- time history of the contact pressure force,

- maximum lifting of the contact wire on the network bracket,

- time history of vertical displacement of the contact wire at each specific point,

- maximum and minimum vertical displacement of the point of contact,

- time history of vertical displacement of each point of the pantograph model,

- percentage of contact loss between the pantograph contact strip and the contact wire. 
The overhead contact line in the reference model is defined as a supporting system with one contact wire. The model consists of ten identical spans. The fifth and sixth spans of the network model are analysed. Calculations should be made for one pantograph traveling at $250 \mathrm{~km} / \mathrm{h}$ and $300 \mathrm{~km} / \mathrm{h}$. Derived from the norm [4], the values of geometrical and mechanical parameters of the reference model, i.e. upper contact line and pantograph, are given in Table 1. The limit norm values with which the obtained simulation results should be compared, are presented in the further part of the article, in the table with the results of the initial validation calculation method (Table 2).

Tab.1.: Characteristics of the reference model defined by the standard [4]

\begin{tabular}{|c|c|c|c|}
\hline Unit weight of the lifting rope & $1.07 \mathrm{~kg} / \mathrm{m}$ & Pantograph speeds & $\begin{array}{l}250 \mathrm{~km} / \mathrm{h} \\
300 \mathrm{~km} / \mathrm{h}\end{array}$ \\
\hline Tension of the carrying rope & $16 \mathrm{kN}$ & $\begin{array}{l}\text { Weight of the pantograph } \\
\text { head }\end{array}$ & $7.2 \mathrm{~kg}$ \\
\hline $\begin{array}{l}\text { Unit weight of the contact } \\
\text { wire }\end{array}$ & $1.35 \mathrm{~kg} / \mathrm{m}$ & $\begin{array}{l}\text { Weight of the pantograph } \\
\text { frame }\end{array}$ & $15.0 \mathrm{~kg}$ \\
\hline Contact wire tension & $20 \mathrm{kN}$ & $\begin{array}{l}\text { The static pressure of the } \\
\text { pantograph }\end{array}$ & $120 \mathrm{~N}$ \\
\hline Stiffness of stretched hanger & $100 \mathrm{kN} / \mathrm{m}$ & $\begin{array}{l}\text { Stiffness of the upper } \\
\text { pantograph spring }\left(k_{1}\right)\end{array}$ & $4200 \mathrm{~N} / \mathrm{m}$ \\
\hline The length of the span & $60 \mathrm{~m}$ & $\begin{array}{l}\text { Stiffness of the lower } \\
\text { pantograph spring }\left(k_{2}\right)\end{array}$ & $50 \mathrm{~N} / \mathrm{m}$ \\
\hline The number of spans & 10 & $\begin{array}{l}\text { Parameter of upper } \\
\text { pantograph dumper }\left(c_{1}\right)\end{array}$ & $10 \mathrm{Ns} / \mathrm{m}$ \\
\hline $\begin{array}{l}\text { Number of hangers in the } \\
\text { span }\end{array}$ & 9 & $\begin{array}{l}\text { Parameter lower pantograph } \\
\text { dumper }\left(c_{2}\right)\end{array}$ & $90 \mathrm{Ns} / \mathrm{m}$ \\
\hline Static contact pressure $(F)$ & $120 \mathrm{~N}$ & $\begin{array}{l}\text { Stiffness of the contact spring } \\
\left(k_{\mathrm{c}}\right)\end{array}$ & $50 \mathrm{kN} / \mathrm{m}$ \\
\hline Aerodynamic strength & $0 \mathrm{~N}$ & $\begin{array}{l}\text { Number of contact wire } \\
\text { damping }\end{array}$ & $0 \%$ \\
\hline
\end{tabular}

\section{Specification of additional simulation input data}

The calculation method used requires additional data that are not specified in the standard [4]. These include some physical parameters of the pantograph system - traction network, i.e. axial rigidity of the carrier rope, damping characteristics of the carrier rope and contact wire, as well as parameters of the numerical method, i.e. the number of basic functions used to approximate displacements, length of the numerical integration step.

The axial rigidity of the carrier rope was adopted based on the test of the impact of the value of this parameter on the results of calculations. Considering the values characteristic for the practical use of overhead contact networks, it was assumed that Young's modulus varies in the range of $115 \div 130 \mathrm{GPa}$, as for copper $\mathrm{Cu}$-ETP, which is one of the typical materials used to make lifting ropes, and the cable cross sections assume values from the range of $65 \div 120$ $\mathrm{mm}^{2}$. In order to shorten the test calculation time, the length of the network model has been reduced to three spans. The test has shown that over 2.5 times change in stiffness in the range of $7.5 \div 19.5 \mathrm{MN}$ ) causes slight changes in the lift of the contact wire on the network bracket up to $10 \%$ of the maximum value and contact pressure up to $4 \%$ of the maximum value. Finally, axial stiffness of the $12.0 \mathrm{MN}$ carrier rope was adopted for further calculations.

One of the most important issues at the stage of testing the simulation method and the selection of input data turned out to be the specification of attenuation characteristics. As the damping measure in the calculation model used, the number of damping, determined 
separately for the carrier rope and the contact wire, was assumed, with the material damping model assumed. In other words, the damping results from the rheological characteristics of the material. The problem of the impact of damping in the material of the carrying rope and the contact wire on the characteristics of forced network oscillations was analysed in detail in [1].

The conclusions from these analyses may be important in the practical use of the simulation method. At the validation stage, it was assumed, according to the guidelines of the standard [4], that the damping in the contact wire is zero, as well as the attenuation in the load-bearing line, which is not determined by the standard.

The SiViPant computer program also requires entering input data, which are the parameters of the numerical method: the number of basic functions used to approximate displacements and the length of the numerical integration step. The determination of the values of these parameters was preceded by a series of convergence tests of solutions whose results are shown in Figs. 3-5. The pantograph speed of $300 \mathrm{~km} / \mathrm{h}$ was adopted for the test calculations.

Fig. 3 and 4 show the dependence of the contact pressure force (Fig. 3) and displacement of the contact wire on the central support of the network (Fig. 4) from the number of basic functions, sines, used for the approximation of displacements in one span and in one direction, vertical or horizontal. The number of base functions $\mathrm{n}$ was varied during the tests in the range from 5 to 35 , but the plots show only three selected solutions, the comparison of which indicate that the use of 20 functions leads to an acceptable accuracy of solutions. Further increase in the number of basic functions no longer significantly affects the accuracy of the results, and causes a significant extension of the calculation time, because the number of basic functions significantly affects the size of the task, and therefore its computational complexity. The total number of base functions in the task, when approximating the vertical and horizontal displacements of the lifting rope and the vertical contact wire, is $3 n \times$ number of spans, i.e. in the analysed case is 600 , when $n=20$. Due to the acceptable calculation time and accuracy of the obtained results, the optimal number of basic functions for further calculations was assumed to be 20 . The tests were carried out in a 10degree damped arrangement.

Fig. 5 shows the dependence of the contact pressure force on the numerical integration step length. This parameter was studied in the range of $0.001 \div 0.00001 \mathrm{~s}$. Due to the very good convergence of solutions, $0.001 \mathrm{~s}$ could be used for further calculations, beneficial due to the shortest simulation time. This test was performed on a three-span section, the pantograph speed was $300 \mathrm{~km} / \mathrm{h}$. To shorten the calculation time, this test was performed for a linear network model in which the hangers carry both tension and compression. 


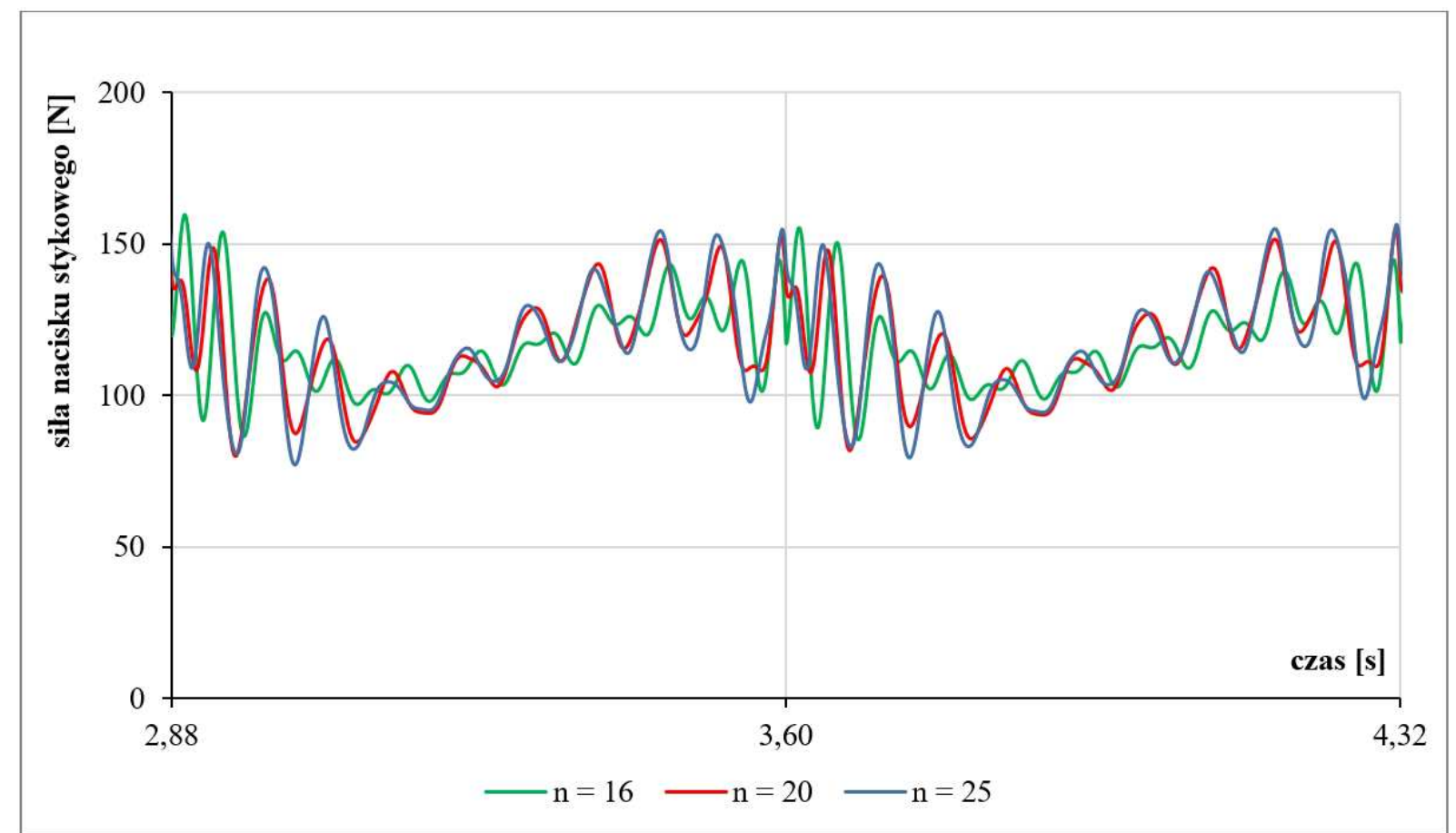

3. Changes in the contact pressure force during the passage of the pantograph through the fifth and sixth spans, depending on the number of basic functions used for the approximation of displacements

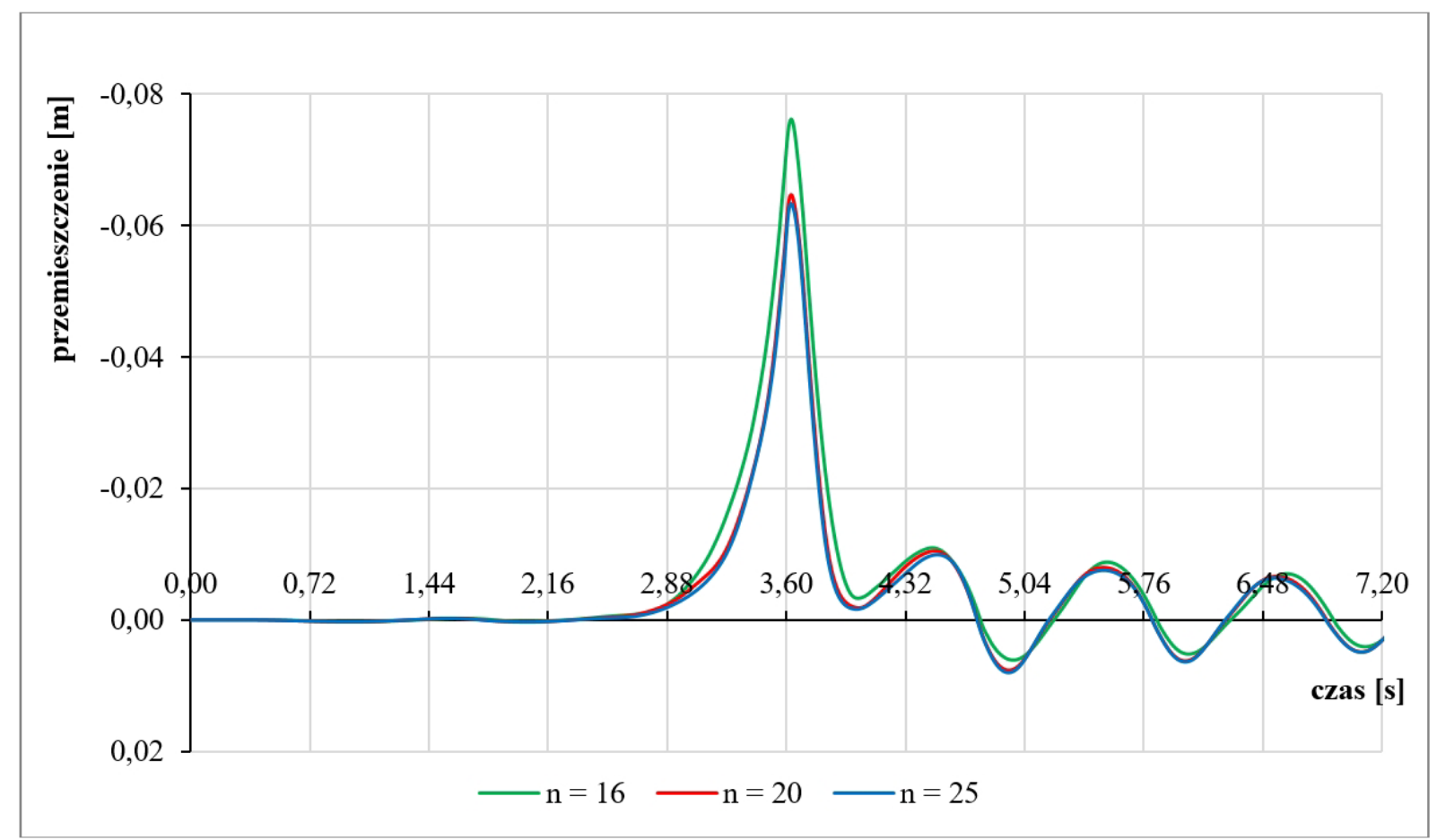

4. Vibrations of the contact wire on the central support of the network between the fifth and the sixth bays, depending on the number of basic functions used to approximate the displacements 


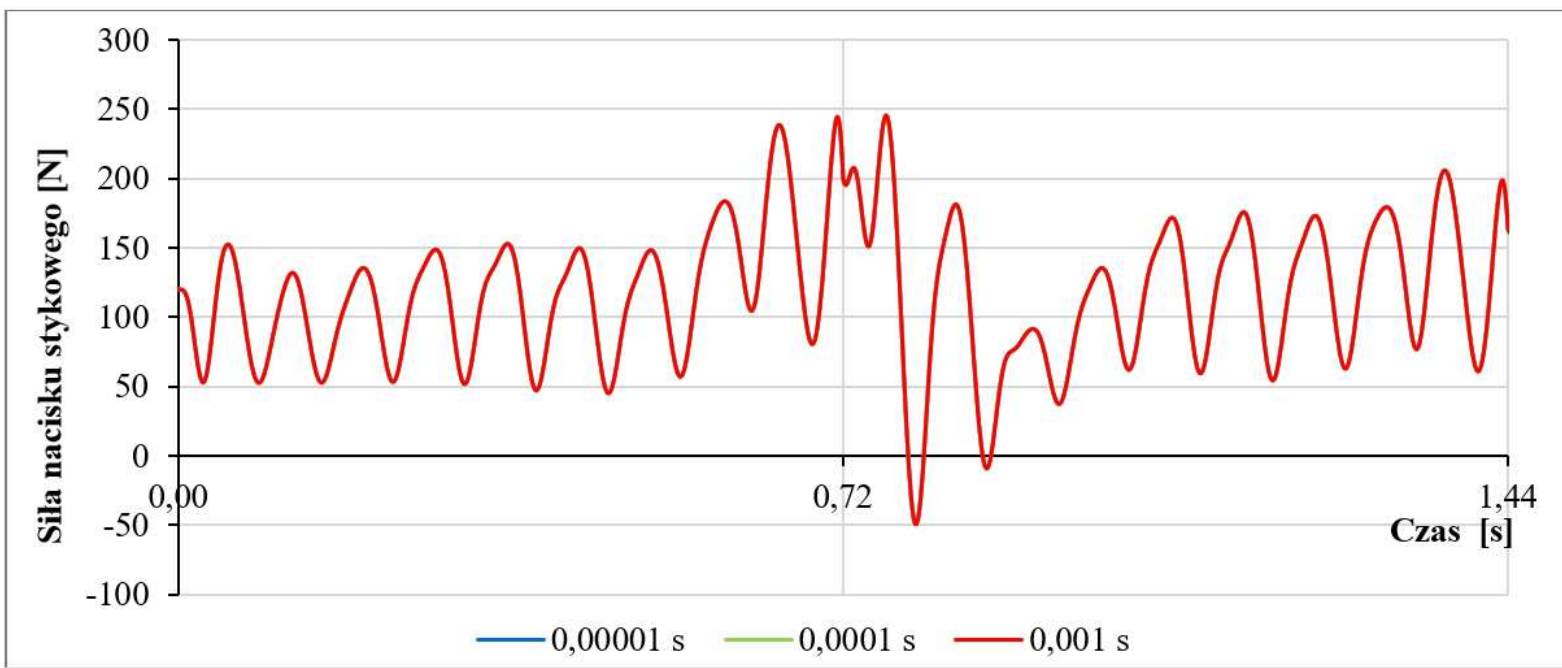

5. Changes in the contact pressure force within the first and second spans, depending on the length of the numerical integration step in three-span network model

\section{The results of the initial validation}

Table 2 presents the resultant values of the output required by the standard [4], which were determined for the reference model by means of the proposed simulation method. The table shows the results for both the required pantograph movement speeds: $250 \mathrm{~km} / \mathrm{h}$ and $300 \mathrm{~km} / \mathrm{h}$, and compares them to the standard limits in which the simulation results determined by the validated method should be located. The green colour indicates the values falling within the standard limits, while the red colour indicate values exceeding the standard limits. The evaluation of the results presented in the table was carried out at the end of the work in the summary.

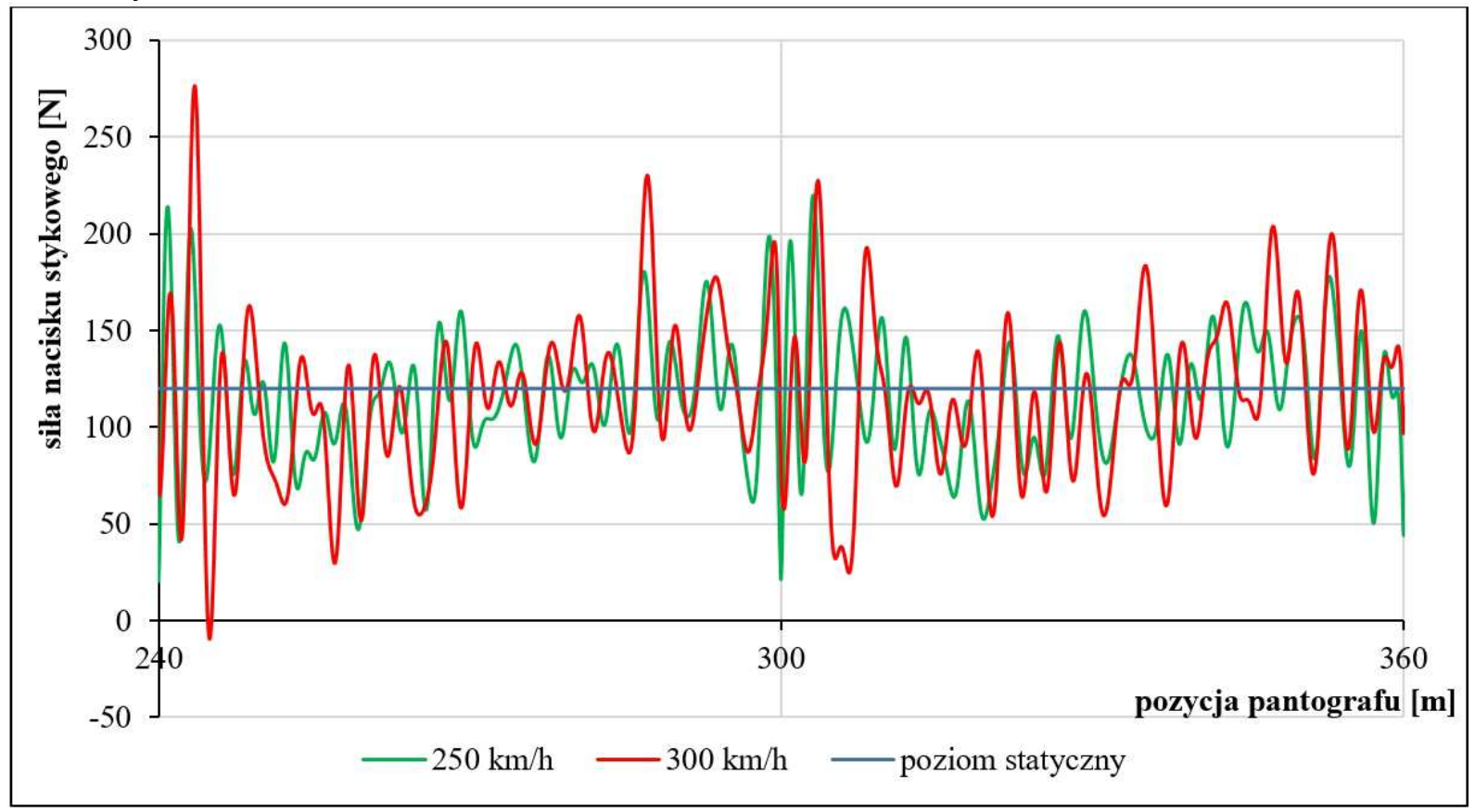

6. Time history of the contact pressure force during passage through the fifth and sixth span of the network at different pantograph traffic speeds

Fig. 6 compares the time histories of changes in the contact pressure force during the passage of the pantograph through the fifth and sixth span of the network model, generated at 
two driving speeds. The two waveforms shown are related to the level of static force $120 \mathrm{~N}$. As can be seen in the figure, an increase in pantograph speed up to $300 \mathrm{~km} / \mathrm{h}$ results in a marked increase in local peaks in contact pressure, compared to a speed of $250 \mathrm{~km} / \mathrm{h}$. This increase in local peaks does not have a significant impact on the mean value of force, but as it is easy to predict, results in an increase in the standard deviation from $31 \mathrm{~N}$ to almost $40 \mathrm{~N}$ (Table 2).

Tab.2. Comparison of simulation results with the limit values

\begin{tabular}{|c|c|c|c|c|c|c|}
\hline & \multirow{2}{*}{ Calculations } & \multicolumn{2}{|c|}{ By norm } & \multirow{2}{*}{ Calculations } & \multicolumn{2}{|c|}{ By norm } \\
\hline & & $\min$ & $\max$ & & $\min$ & $\max$ \\
\hline Pantograph speed $[\mathrm{km} / \mathrm{h}]$ & \multicolumn{3}{|c|}{250} & \multicolumn{3}{|c|}{300} \\
\hline $\begin{array}{l}\text { The arithmetic mean of the contact } \\
\text { pressure force }[\mathrm{N}]\end{array}$ & 116.1 & 110 & 120 & 116.2 & 110 & 120 \\
\hline $\begin{array}{l}\text { Standard deviation of the contact } \\
\text { pressure force }[\mathrm{N}]\end{array}$ & 31.0 & 26 & 31 & 39.8 & 32 & 40 \\
\hline $\begin{array}{l}\text { Statistical maximum contact pressure } \\
\text { force }[\mathrm{N}]\end{array}$ & 209.2 & 190 & 210 & 235.6 & 210 & 230 \\
\hline $\begin{array}{l}\text { Statistical minimum contact pressure } \\
\qquad[\mathrm{N}]\end{array}$ & 23.1 & 20 & 40 & -3.2 & -5 & 20 \\
\hline Actual maximum contact force $[\mathrm{N}]$ & 220.0 & 175 & 210 & 276.5 & 190 & 225 \\
\hline $\begin{array}{l}\text { Actual minimum contact pressure } \\
\text { force }[\mathrm{N}]\end{array}$ & 20.2 & 50 & 75 & -9.5 & 30 & 55 \\
\hline Percentage of contact loss [\%] & $\mathbf{0}$ & \multicolumn{2}{|c|}{0} & 0.35 & \multicolumn{2}{|c|}{0} \\
\hline $\begin{array}{c}\text { Maximum lift on the middle support } \\
\text { of the network [mm] }\end{array}$ & 71.1 & 48 & 55 & 74.4 & 55 & 65 \\
\hline
\end{tabular}

Calculated statistical measures of the solution, i.e. average value and standard deviation, do not give information on the probability distribution of the contact pressure, i.e. the frequency of individual strength values. This information gives an approximate empirical distribution in the form of a histogram. Fig. 7 and 8 show the histograms of the contact pressure force determined on the basis of the time courses shown in Fig. 6, which include passage of the pantograph through spans No. 5 and 6. The vertical axis determines the percentage share of these values in the tested course of the contact pressure force. These values are located in successive compartments on the horizontal axis, with the division into 5 $\mathrm{N}$ intervals assumed. The shape of the histogram determined at $250 \mathrm{~km} / \mathrm{h}$ (Figure 7) shows that the distribution of the pantograph dynamic pressure force is unimodal, close to the normal Gaussian. The strength values are concentrated around the average value about $116 \mathrm{~N}$, close to the static level $120 \mathrm{~N}$. In the case of a higher speed $300 \mathrm{~km} / \mathrm{h}$, the concentration of the contact pressure force around the average value is much smaller and the distribution is difficult to be considered Gaussian (Figure 8). Based on the presented histograms, you can easily determine the percentage of contact loss, counting the frequency of the force value equal to zero or less and referring to the total number of values. 


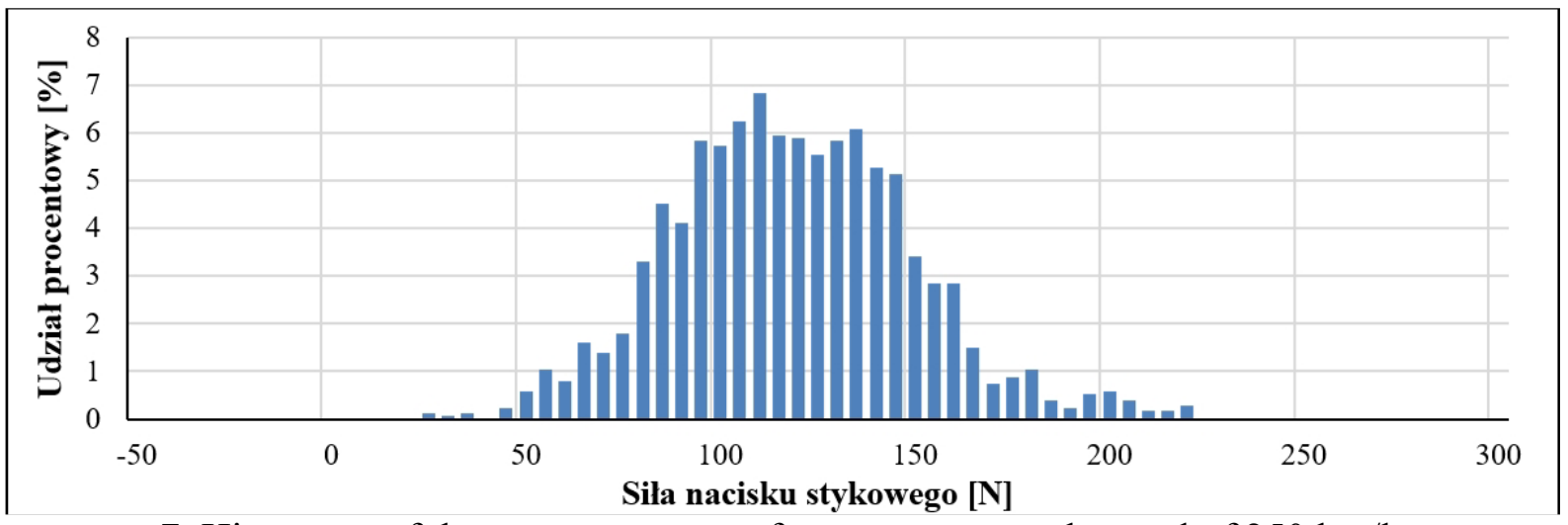

7. Histogram of the contact pressure force at pantograph speed of $250 \mathrm{~km} / \mathrm{h}$

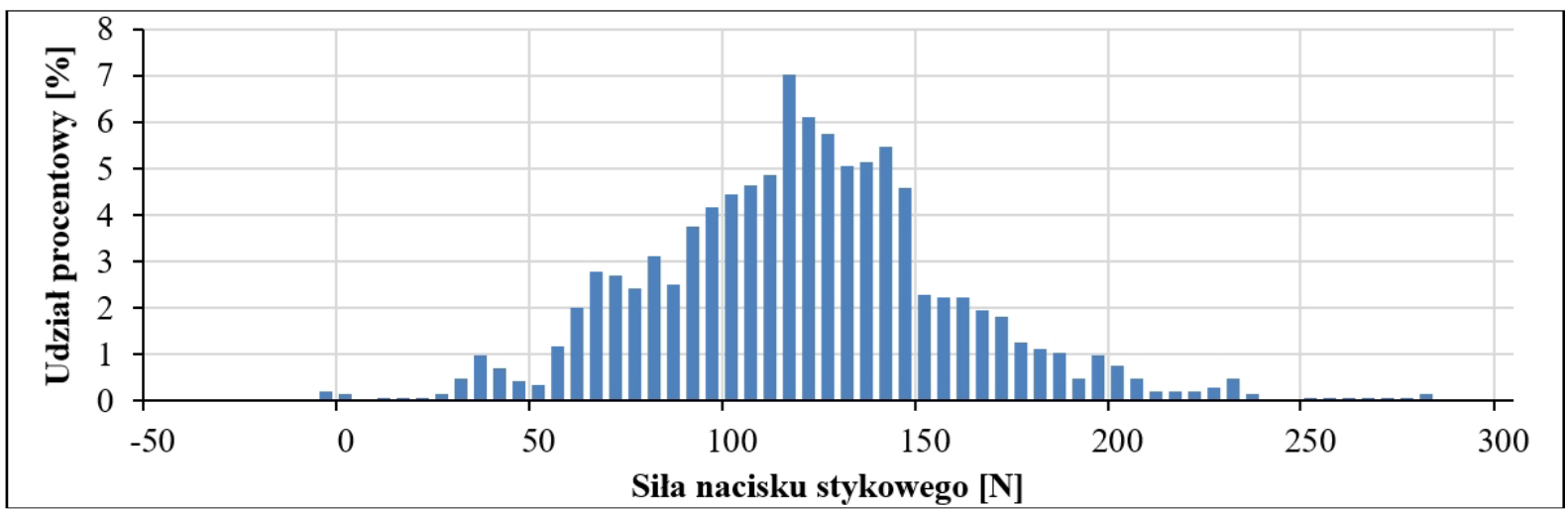

8. Histogram of the contact pressure force at the pantograph movement speed $300 \mathrm{~km} / \mathrm{h}$

Fig. 9 and 10 show example vibrations of the traction network, pantograph system, generated for two considered pantograph travel speeds along the network. The maximum and minimum values of displacement can be read from the vibrations, and the nature of vibrations can be determined. For example, in Fig. 9 the oscillating increase in the contact wire rise to the maximum value is visible first, then, after the pantograph travels through the observed network point, the elevation decreases rapidly and after the pantograph moves away, free vibrations appear. The cable vibration observation point is located on the network bracket, on the extraction arm according to the terminology used in the TSI [6], between the fifth and sixth span. The influence of the pantograph movement speed on the cable lift is generally smaller than in the case of the contact pressure force. 


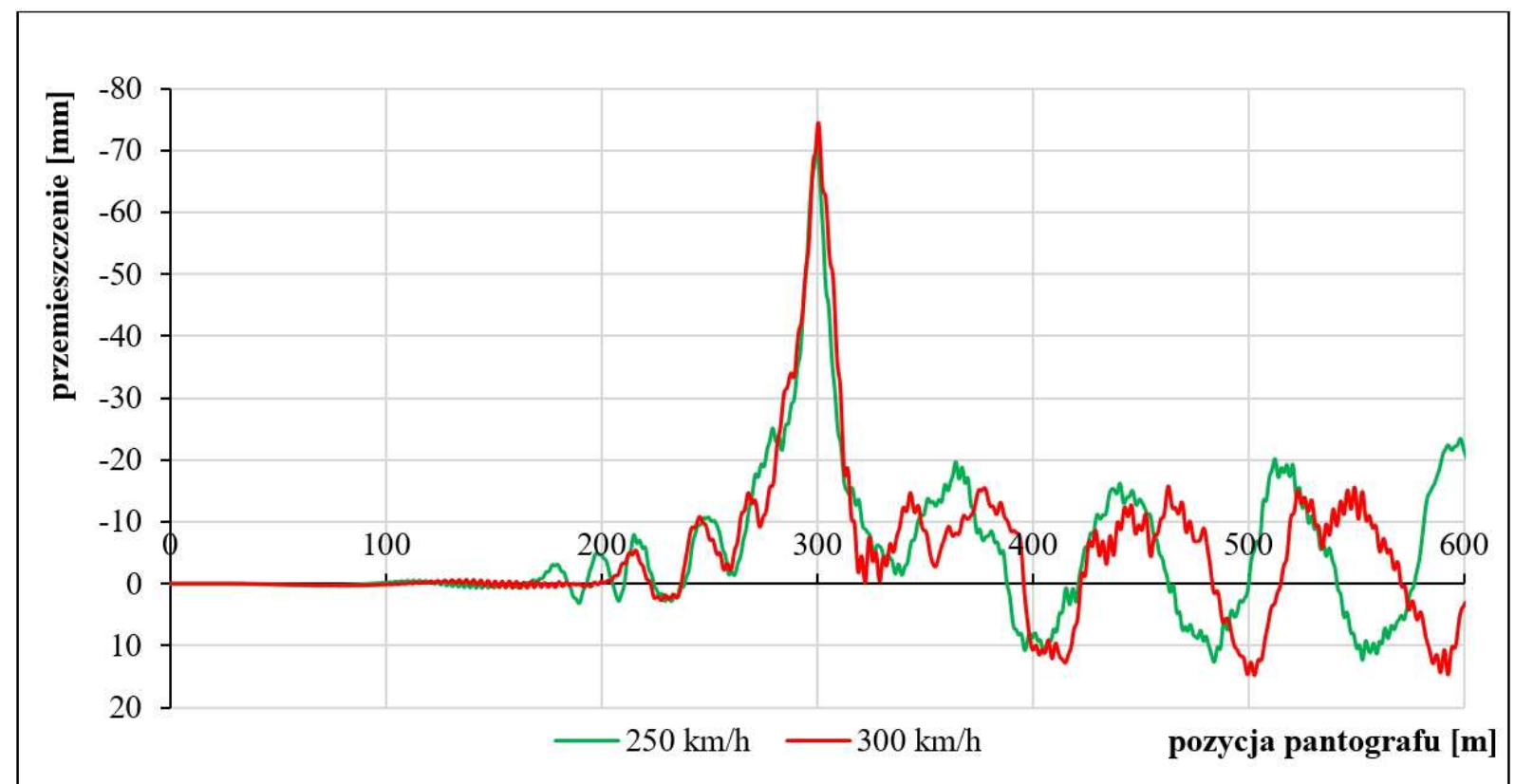

9. Time history of vertical displacement of the contact wire at the centre network bracket at different pantograph movement speeds. The negative values mean cable lift.

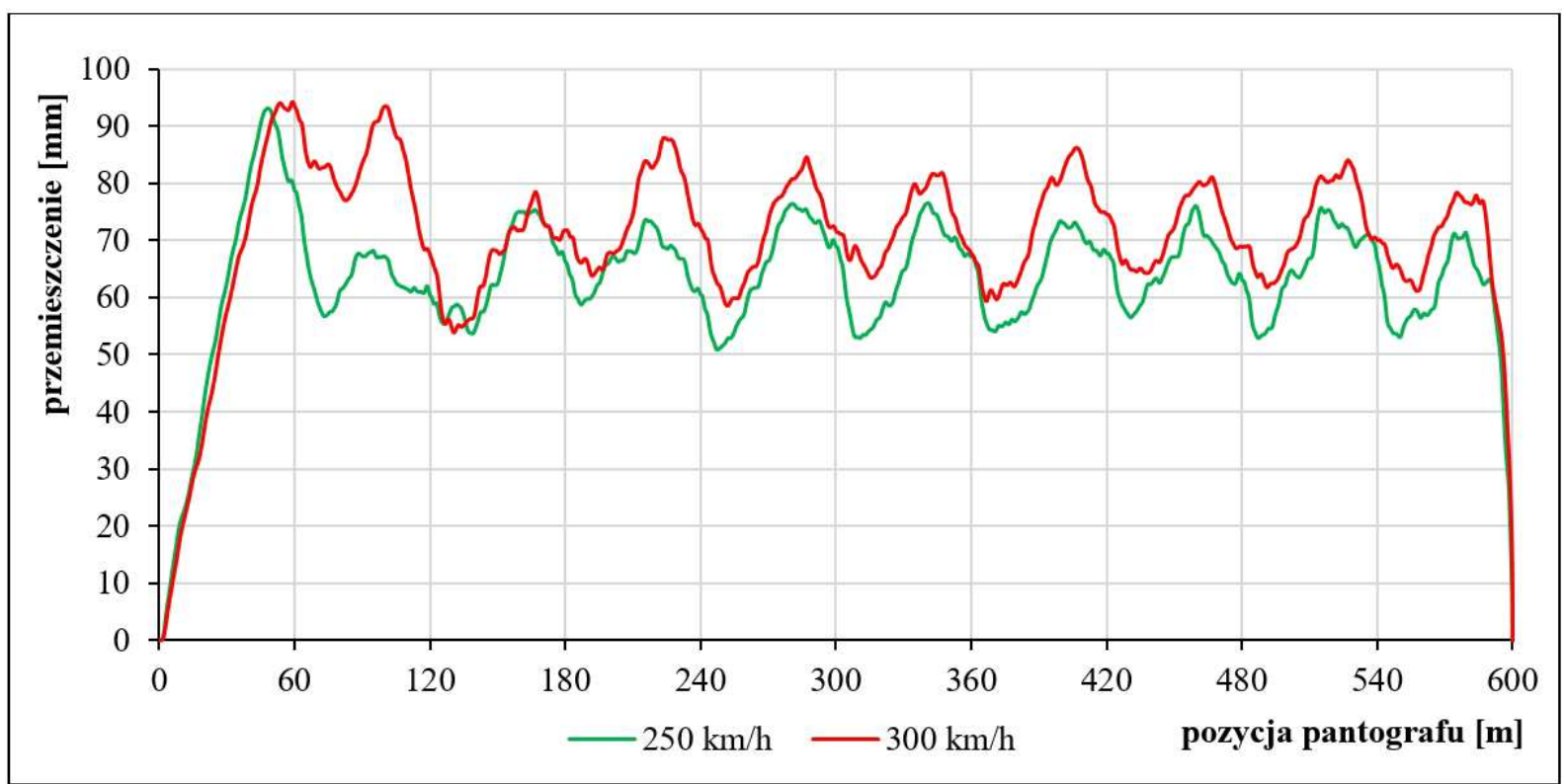

10. Time history of displacement of the slider at different pantograph movement speeds

Fig. 10 shows the time history of the vertical vibrations of the pantograph head during travel through the entire ten-span model of the network. The extreme fragments of the runs are illustrated respectively: the initial transient state resulting from the entry of the pantograph into the first span and the final stage resulting from the pantograph exit from the last span of the network. Both of these fragments are an undesirable effect of the adopted calculation model, which assumes that the ends of the contact wire in the outermost bands are fixed points and dynamic displacements of the pantograph elements before entering the set of ten spans and are zero after the exit. The middle fragments of the graphs, i.e. the position of the pantograph between $240 \mathrm{~m}$ and $360 \mathrm{~m}$, illustrate the course of vibration of the pantograph head passing through the fifth and sixth spans. These spans, according to the terminology of the standard [4], constitute the "analysed section of the network", i.e. a subset of the total length of the overhead contact model, which is not affected by the initial transient states and 
final effects of the model. As can be seen from Fig. 10, it can only be approximated that the vibrations of the pantograph head within the analysed section are already fixed and repetitive. The extension of the overall length of the network model should be considered.

\section{Conclusions}

The article presents the first attempt to validate the simulation method proposed by the authors in [1] and [2]. The set of results presented in Table 2 is an example of determining the dynamic characteristics of the rail network of electric traction, as defined by TSI Energia. The possibility of obtaining, based on the simulated network vibrations, the output quantities required by the TSI [6] and the standard [4], demonstrates the usefulness of the original calculation method as a tool for practical assessment of the compliance of the dynamic network characteristics with the requirements of the TSI. Due to the fact that the calculation method must be validated in accordance with the standard [4], the results obtained using the input data of the reference model were compared with the norm limits. Some of the results obtained, mainly the average contact pressure, standard deviation or statistical minimum contact pressure, are within the normal range. In other cases, the standard ranges are exceeded slightly. It can be expected that the inclusion of a larger number of iterations in the procedure for determining the non-linear component of the motion equation, compensating for the impact of compression hangers, will lead to a more accurate determination of the output quantities. The influence of the number of iterations in this procedure on the results of the simulation will be analysed in the next stage of the research.

\section{References}

[1] Bryja D., Popiołek A.: Analiza drgań wieszara cięgnowego jako modelu kolejowej sieci trakcyjnej obciążonej ruchem pantografów, Czasopismo Inżynierii Lądowej, Środowiska i Architektury - Journal of Civil Engineering, Environment and Architecture, JCEEA (praca przyjęta do druku).

[2] Bryja D., Prokopowicz: D. Dyskretno-ciągły model obliczeniowy sprzężonego układu dynamicznego: pantograf - napowietrzna sieć trakcyjna. Przegląd Komunikacyjny, 2016, nr 5, s. 44-51.

[3] Dyrektywa Parlamentu Europejskiego i Rady (UE) 2016/797 z dnia 11 maja 2016 r. w sprawie interoperacyjności systemu kolei w Unii Europejskiej.

[4] EN 50318: 2002, Zastosowania kolejowe - Systemy odbioru prądu - Walidacja symulacji oddziaływania dynamicznego pomiędzy pantografem a siecią jezdną górną.

[5] Praca zbiorowa (red. Pawlik M.): Interoperacyjność systemu kolei Unii Europejskiej. Infrastruktura, sterowanie, energia, tabor. Kolejowa Oficyna Wydawnicza, 2015.

[6] Rozporządzenie Komisji (UE) nr 1301/2014 z dnia 18 listopada 2014 r. w sprawie technicznych specyfikacji interoperacyjności podsystemu Energia systemu kolei $\mathrm{w}$ Unii. 